\title{
EL SURGIMIENTO DEL CASE MANAGEMENT Y LA \\ SUPERACIÓN DEL JUEZ DIRECTOR DEL PROCESO: \\ EL PROCESO COMO REFLEJO DE LAS EXIGENCIAS Y PROBLEMAS DE NUESTRA ÉPOCA
}

\author{
THE RISE OF CASE MANAGEMENT AND THE OVERCOMMING \\ OF THE JUDGE AS DIRECTOR OF THE PROCEEDINGS: \\ JUDICIAL PROCEEDINGS AS A REFLECTION OF THE \\ CHALLENGES AND PROBLEMS OF OUR TIME
}

RAMÓN GARCÍA ODGERS*

CLAUDIO FUENTES MAUREIRA**

\section{RESUMEN}

Las exigencias sociales y políticas que recaen sobre los sistemas de justicia y los desafíos que estos deben enfrentar en una época específica determinan la respuesta al crucial problema de la conducción del proceso civil. En esta perspectiva, este trabajo describe someramente aquellas exigencias y desafíos contemporáneos de los sistemas de justicia que han generado un nuevo paradigma en la conducción de los procedimientos, que la doctrina y el derecho procesal comparado denominan case management o judicial case management. Junto con esbozar los rasgos centrales de este nuevo paradigma, se demuestra cómo sus alcances implican la superación del paradigma del juez director del proceso.

\footnotetext{
*Abogado, Doctor en Derecho, P. Universidad Católica de Valparaíso. Profesor de Derecho Procesal e Investigador, Facultad de Derecho Universidad Católica de la Santísima Concepción, Concepción, Chile. Correo electrónico: rgarcia@ucsc.cl. Código Orcid: https://orcid.org/0000-0003-1776-7702.

**Abogado, Magister en Derecho Penal y Procesal Penal, Universidad Diego Portales. Doctor en Derecho (JSD), Stanford University. Profesor de Derecho Procesal e Investigador, Facultad de Derecho Universidad Diego Portales, Santiago, Chile. Correo electrónico: claudio.fuentes@mail.udp.cl. Código Orcid: https://orcid.org/0000-0003-1088-5554.
}

Trabajo recibido el 28 de agosto de 2020 y aceptado para su publicación el 14 de diciembre de 2020 . 
Palabras clave: Case management, Judicial case management, Dirección judicial del proceso, Juez director del proceso, Proceso civil, Derecho procesal.

\section{ABSTRACT}

The social and political demands that fall up on the Justice systems and the problems they must deal with in specific moments in time determine the answer they provide to the crucial issue about who controls and guides the civil proceedings. From this standpoint this article succinctly describes the justice system's contemporary demands and challenges which have generated a new paradigm regarding the control of the judicial proceedings, to which the legal scholarship and comparative procedural law have termed case management or judicial case management. Alongside the presentation of the main features of this new paradigm, the paper shows how it overcomes the judge as director of the proceedings paradigm.

Keywords: Case management, Judicial case management, Judge as director of the proceedings, Judicial directions of the process, Civil procedure, Procedural law.

\section{INTRODUCCIÓN Y PLANTEAMIENTO DEL PROBLEMA}

Una de las preguntas fundamentales sobre el proceso civil dice relación con quién tendrá el poder y la responsabilidad de conducirlo, cuya respuesta resulta determinante para la configuración del modelo de justicia civil. Pero su relevancia no se agota ahí, ya que el desarrollo de los sistemas de justicia muestra que se trata de una interrogante perenne.

Como es sabido, la respuesta original fue que la justicia civil estaba destinada exclusivamente a resolver conflictos de naturaleza eminentemente privada, entre particulares. En esta lógica, el proceso fue concebido como una "cosa de las partes", ${ }^{1}$ asumiéndose como natural que fuesen ellas quienes dirigieran el proceso a su discreción. Por ello, ningún poder fue entregado a

1"En la misma forma que los propietarios en un estado liberal clásico poseen una libertad absoluta para disponer de sus bienes, los litigantes en un litigio civil tienen una libertad absoluta para disponer de sus demandas y del proceso en su conjunto, son los domini litis, los amos de la litigación civil”. 
los jueces para intervenir y acelerar un caso. ${ }^{2}$

Sin embargo, con el pasar del tiempo, cambios sobre el entendimiento de cuáles debían ser los fines del proceso, ${ }^{3}$ y en especial, de una mayor consideración de su carácter público ${ }^{4}{ }^{4}$ surgió la tendencia de establecer un juez activo con el fin de inyectar eficiencia a la litigación. ${ }^{5}$ En nuestros sistemas de tradición continental, este desarrollo se manifestó a través del paradigma, idea o metáfora de la dirección judicial del proceso. ${ }^{6}$

Es interesante notar que algunos estudios procesales pongan todo el énfasis en los méritos conceptuales de estas teorías, como si existiese entre ellas una suerte de competencia, obviando que en definitiva estas son social, política y culturalmente contingentes. En otras palabras, entre ambos paradigmas sobre quién debe dirigir el proceso, antes que una competencia conceptual, lo que existe es una evolución que no depende mayormente de los avances del derecho procesal, sino que, más bien, en la capacidad de éste de proveer al proceso de herramientas conceptuales que le permitan adaptarse a nuevas realidades sociales. Así, tanto el paradigma de la conducción del proceso por las partes como el de juez director, son, sobretodo, respuestas a las exigencias sociales y políticas que han recaído sobre los sistemas de justicia y los problemas que han debido enfrentar en una época determinada.

Uzelac, Alan, "Goals of Civil Justice General Report”, en: Maleshin, D. (Ed.), Civil procedure in cross-cultural dialogue, International Association of Procedural Law Russian Federation, Statut, Moscú, 2012, p. 115. (La traducción es nuestra, al igual que todas las citas de obras cuyo idioma original no es el español)

${ }^{2}$ Cappelletti, Mauro; Garth, Bryant, International encyclopedia of comparative law XVI, Mohr Siebeck, Tubingen; Martinus Nijhoff Publishers, Leiden, 1987, T.I., p. 23.

${ }^{3}$ GARCia Odgers, Ramón, "El surgimiento del judicial case management: una síntesis evolutiva del control judicial del proceso civil en Europa", Revista de Estudios Histórico Jurídicos, 2019, N 41, pp. 179-205.

${ }^{4}$ Cappelletti y Garth, cit. (n. 2), pp. 23 y ss.

${ }^{5}$ VAN RHEE, C.H., Judicial case management and efficiency in civil litigation, Intersentia, Antwerp, Oxford, Portland, 2008. El término "eficiencia" no se refiere exclusivamente a la finalidad de conseguir un ahorro de recursos, esfuerzos y tiempo, sino que a la relación entre un fin y los medios usados para conseguirlo, en el entendido que es un ideal lograr dicho fin, cualquiera este sea, con el menor uso de recursos posible. En este sentido, es posible lograr una decisión "justa" o "correcta" de manera eficiente. Hacemos esta aclaración porque en nuestro medio un sector de la doctrina utiliza una noción peyorativa de esta, limitándola a la simple disminución de gastos y mejora de las estadísticas judiciales. Véase como ejemplos: Tavolari, Raúl, "Prólogo", en: Delgado, J.; NúÑez, R. (Coords.), Recursos procesales. Problemas actuales., DER Ediciones, Chile, 2017, pp. 4 y ss.; y Palomo, Diego, "Sobre la conducta procesal de algunos jueces. De vuelta con la unidimensionalidad de la eficiencia y la potestad conciliatoria como excusas", Ius et Praxis, 2014, Año 20, Nº 1, pp. 382 y ss.

${ }^{6}$ López, Diego, Nuevas tendencias en la Dirección Judicial del Proceso, Módulo de Formación, Escuela judicial "Rodrigo Lara Bonilla", Colombia, 2004, pp. 48 y ss. 
Cappelletti, hace más de 40 años atrás, sintetizaba esta idea señalando que el proceso "es el fiel espejo de las principales exigencias, problemas y pruebas de nuestra época, del inmenso desafio de nuestro tiempo". ${ }^{7}$

En la actualidad, cambios sociales y políticos, así como los desafíos y problemas que enfrentan los sistemas de justicia, presentan elementos, desarrollos y tendencias que configuran un nuevo paradigma en la conducción de los procedimientos ${ }^{8}$ denominado en el derecho comparado como case management, y cuya esencia "es que el sistema judicial en su conjunto y los tribunales en los casos individuales, regulan el contenido y el progreso de la litigación". 9 .

Este busca responder al grave problema de los tribunales que deben lidiar con gigantescos volúmenes de casos y articular diversos fines del proceso, para lo cual se apoya de nuevos conceptos y principios como la proporcionalidad, la cooperación y la flexibilidad de los procedimientos.

El case management ha tomado un lugar principal en la discusión procesal moderna, ${ }^{10}$ no sólo en Europa ${ }^{11}$ y en Norte América, ${ }^{12}$ sino que a nivel global, ${ }^{13}$ al punto de identificarlo como una de las características definitorias de los sistemas de justicia civil en todo el mundo. ${ }^{14}$ En la actualidad, ha sido incorporado o discutida su incorporación en un gran número de jurisdicciones $-\mathrm{y}$ en textos que promueven la armonización

\footnotetext{
${ }^{7}$ Cappelletti, Mauro, "Social and Political Aspects of Civil Procedure: Reforms and Trends in Western and Eastern Europe", Michigan Law Review, 1971, Vol. 69, № 5, p. 886.

${ }^{8}$ La expresión "paradigma" es utilizada en este documento como el conjunto de prácticas y saberes que definen una disciplina en un período específico. KuHN, Thomas S., La estructura de las revoluciones científicas, Fondo de Cultura Económica, México D.F., 2010, 3ª edición, pp. 70 y ss.

${ }^{9}$ Andrews, Neil, English civil procedure. Fundamentals of the new civil justice system, Oxford University Press, New York, 2003, p. 337.

${ }^{10}$ VAN Rhee, C. H., cit. (n. 5).

${ }^{11}$ Van RheE, C. H., "Case management in Europe: A modern approach to civil litigation", International Journal of Procedural Law, 2018, Vol. 8, No 1, p. 77 y 78.

12 "...el incremento del case management constituye el cambio más importante en el procedimiento judicial norteamericano en los últimos cincuenta años.". MArcus, Richard L., "Reassessing the magnetic pull of mega cases on procedure", DePaul Law Review, 2001, № 51, p. 472.

13 "Las palabras clave de muchas reformas en diferentes partes del mundo, desde comienzos del siglo XXI son proporcionalidad, acceso a la justicia y case management." UzeLAC, Alan; VAN RHEE, C.H., "The Metamorphoses of Civil Justice and Civil Procedure: The Challenges of New Paradigms - Unity and Diversity", en: Uzelac, A.; Van Rhee, C.H. (Eds.), Transformation of Civil Justice, Springer International Publishing AG, Switzerland, 2018, p. 13.

${ }^{14}$ SORABлI, John, “Managing claims", Tiajin Conference (IAPL), International Association of Procedural Law, Tiajin, 2017, p. 2.
} 
del procedimiento civil- ${ }^{15}$ como mecanismo para enfrentar los problemas contemporáneos de los sistemas de justicia y mejorar la eficiencia. ${ }^{16}$

En contraste, la literatura latinoamericana sobre case management es muy escasa aunque el tema comienza a adquirir creciente relevancia en diversos países como Colombia, ${ }^{17}$ Perú, ${ }^{18}$ Argentina ${ }^{19}$ y Brasil.${ }^{20}$ En Chile, la doctrina ha comenzado a hablar de este instituto, observándose un desarrollo mayor sólo en los últimos años. ${ }^{21}$

Con todo, en nuestro continente no hay literatura que aborde el tema en forma sistemática y con autonomía conceptual, salvo una excepción. ${ }^{22}$ Los pocos textos disponibles frecuentemente traducen la expresión case management como "dirección del proceso", 23 "dirección e impulso", ${ }^{24}$

${ }^{15}$ Como en los Principios y Reglas Unidroit/ALI donde "se recogen las principales tendencias del derecho procesal contemporáneo, entre otros, el rol de las partes y los abogados, en el contexto del case management.". VAN RHEE, C.H., "Obligations of the parties and their lawyers in civil litigation: The ALI/UNIDROIT principles of transnational civil procedure", en: AdOLPHSEN, Jens; GoEBEL, Joachim; HaAs, Ulrich; Hess, Burkhard; Kolmann, Stephan; Würdinger, Markus, (Eds.), Festschrift für Peter Gottwald zum 70 Geburtstag, C.H. Beck, München, 2014, pp. 689-699.

${ }^{16}$ CABral, Antonio, "News trends and perspective on case management: proposals on contract procedures and case assignment management", Tiajin Conference (IAPL), International Association of Procedural Law, Tiajin, 2017, p. 1.

${ }^{17}$ Véase como ejemplo: LóPEZ, cit. (n. 6), pp. 1-205.

${ }^{18}$ Véase como ejemplo: FandiÑo, Marco; Sucunza, Matías, "Cambios organizativos y nuevo rol de los operadores como premisas para el éxito de la oralidad en la justicia civil del Perú", Gaceta Civil \& Procesal Civil, 2019, No 74, pp. 131-141.

${ }^{19}$ Por ejemplo, Отегza, Eduardo, "Case management and judicial management: five perspectives with a common aim", International Journal of Procedural Law, 2018, Vol. 8, No 1, pp. 5 y ss. y BerizonCE, Roberto, "El principio de legalidad formal bajo el prisma de la constitución "normatizada", Revista del Instituto Colombiano de Derecho Procesal, 2014, N 40, pp. 68 y ss.

${ }^{20}$ El Código de Procedimiento Civil de 2015 incorporó el case management en su artículo 139. DidiER JR., Fredie; ArRudA, Teresa (Coords.), CPC Brasileiro Traduzido para a lingua espanhola, Código de Proceso Civil Brasleiño de 2015, traducao Renzo Cavani, Editorial Juspodivm, Salvador, 2018.

${ }^{21}$ RIEGO, Cristian, "El sistema de case management y su aplicación en el contexto chileno", Revista Sistemas Judiciales, 2014, Vol. 18, pp. 76 y ss.

${ }^{22}$ García Odgers, Ramón, "El case management en perspectiva comparada. Teoría, evolución histórica, modelos comparados y un caso en desarrollo", Tirant Lo Blanch, Valencia, 2020, pp. 1-652.

${ }^{23}$ Por ejemplo, en ResniK, Judith, "Los jueces como directores del proceso" (trad. cast. de María Emilia Mamberti y Francisco Verbic), Revista de Processo, 2017, Vol. 42, № 268, pp. 189 y ss., que traduce el texto de ResniK, Judith, "Managerial judges", Harvard Law Review, 1982, N 96, N 2.

${ }^{24}$ Bravo, Pablo, "Hacia la reforma del proceso civil en Chile", Revista General de Derecho Procesal (Iustel), 2013, $\mathrm{N}^{\circ} 29$ (enero), p. 17. 
"dirección y control del proceso", ${ }^{25}$ "gestión y dirección del proceso", ${ }^{26}$ y otras combinaciones similares. ${ }^{27}$

Como puede apreciarse, estas traducciones literales o conceptuales, confunden el case management con la dirección judicial del proceso y los poderes del juez, ${ }^{28}$ lo que oculta gran parte de su complejidad conceptual y evolutiva y sobre todo, no permiten entender, a cabalidad, los alcances del instituto. $^{29}$

La expresión "case management", envuelve un cambio radical en la comprensión de la litigación civil, sintetizando los intentos de adaptación de los sistemas de justicia a los desafíos y tendencias de nuestra época, desafiando conceptos y premisas de la teoría procesal más tradicional, aun dominante en las legislaciones procesales civiles latinoamericanas.

Este trabajo viene a llenar un vacío en nuestra doctrina procesal civil, en dos sentidos. En primer lugar, dando cuenta de este proceso evolutivo en la teoría procesal comparada. En segundo lugar, describiendo como los desafíos y problemas contemporáneos de los sistemas de justicia dieron pie a dicha evolución. Para lo anterior, este documento comienza mediante la descripción de las principales consideraciones teóricas del case management, con el objetivo de explicar cómo este marca una superación del paradigma del juez director o dirección judicial del proceso..$^{30}$ Para estos efectos, desarrollamos (II) una síntesis conceptual del case management, (III) y de sus dimensiones más relevantes, (IV) para visualizar los principales problemas y desafíos que los sistemas de justicia enfrentan y donde éste se erige como

\footnotetext{
${ }^{25}$ TARUfFo, Michele, "Poderes probatorios de las partes y del juez en Europa", DOXA, Cuadernos de Filosofia del Derecho, 2006, $\mathrm{N}^{\circ} 29$, p. 260.

${ }^{26}$ Pérez Ragone, Álvaro, "La revalorización de la audiencia preliminar o preparatoria: Una mirada desde la justicia distributiva en el proceso civil", Revista de Processo, 2016, Vol. 252, pp. 405 y ss.

${ }^{27}$ Como "dirección formal y material del proceso", en la traducción de Pérez Ragone y García Odgers de ANDREws, Neil, "La combinación de la administración pública y privada de la justicia civil", Revista de Derecho P. Universidad Católica de Valparaíso, 2012, Vol. XXXIX, pp. 254 y ss.

${ }^{28}$ VAn Rhee, C.H., "Tradiciones europeas en el procedimiento civil: Una introducción", Revista de Estudios de la Justicia, 2011, No 15 (trad. cast. de Graciela Hermosilla Riobó y Carolina Sandoval Flores), pp. 30 y ss.

${ }^{29}$ JeUland, Emmanuel, "Toward a New Court Management and the rise of the Court manager-General Report”, Tiajin Conference (IAPL), International Association of Procedure Law, Tianjin, 2017, pp. 1 y ss.

${ }^{30}$ En la perspectiva comparada el case management reconoce diferencias y matices dependiendo del sistema procesal en el que se examine. Sin embargo, es posible delinear un modelo teórico que identifique su contenido y el rol que cumple, a partir de sus rasgos más relevantes, lo que es desarrollado en este documento.
} 
respuesta, seguido de la (V) presentación de los principios procesales que esta institución conlleva para su funcionamiento. A continuación, se hará un (VI) resumen comparativo entre la dirección judicial del proceso y el case management para mostrar cuales son los rasgos que permiten identificar su autonomía conceptual y por qué este nuevo instituto supone una evolución respecto de aquel. Al finalizar, se enunciarán (VII) algunas reflexiones a modo de conclusión.

\section{CONCEPTOS SOBRE CASE MANAGEMENT}

Entendemos que el case management consiste en la gestión y control judicial de la litigación para alcanzar los fines relevantes del sistema de justicia. Esta gestión y control intencionado hacia los fines del sistema supone que no todos los casos alcanzarán una sentencia que resuelva el fondo del asunto. Desarrollaremos estas ideas en las líneas que siguen.

La gestión de la litigación implica considerar el valor y/o peso de un caso específico dentro del universo de causas que actualmente son conocidas por los tribunales y de aquellas que en el futuro merecerán igualmente la atención y, por tanto, la asignación proporcional de los limitados recursos judiciales. Esta determinación se verifica de acuerdo a criterios normalmente asociados a su importancia, complejidad, urgencia, cuantía y situación económica de las partes con el fin de asegurar una solución justa y equitativa para cada causa (actual y futura) que conozca el sistema. ${ }^{31}$

El control de la litigación implica que el Poder Judicial y cada uno de los tribunales se hacen cargo de la distribución, racionamiento y racionalización de los recursos del sistema, especialmente, del tiempo del juez o tribunal.

En este contexto los tribunales, tanto como organización, así como cada uno de las y los jueces que lo conforman, pasan a convertirse en responsables del conjunto de casos y del progreso del caso individual. La clave es que el tribunal actúa como un catalizador para promover un tratamiento eficaz y eficiente de los casos a través del sistema, ya que los jueces son los únicos capaces de establecer el ritmo del litigio, independiente de los intereses de las partes, con el fin de garantizar un tratamiento justo, proporcional y oportuno de los casos. Como se observa, esta opción viene a constituirse en

${ }^{31}$ PÉrez, cit. (n. 26), p. 410. 
una reacción a la gestión del caso por las partes o sus abogados, donde lo único que importa o interesa es su propio caso.

Ahora bien, la idea de control judicial en la experiencia comparada no significa necesariamente la participación directa, exclusiva y excluyente de un juez en el procesamiento completo de un caso. En el case management el grado de intervención judicial puede ser total, incluyendo un manejo y supervisión de todo el desarrollo del caso, o bien, limitada a una o más etapas críticas del proceso o sólo respecto de ciertos y determinados casos, por ejemplo, los más complejos. También, es posible distinguir distintos niveles de intensidad y espacios para la discrecionalidad judicial ${ }^{32}$ y la incorporación de una importante intervención de las partes, como se verá.

Lo importante es que el tribunal y/o el juez tome la responsabilidad y el control sobre el caso, y además, esté en condiciones de supervisar su progreso a través de sus etapas. Esta actividad puede ejercerse en coordinación con funcionarios del tribunal, bajo la responsabilidad del juez. Por ello, también se ha entendido el case management como "la intervención consciente de los funcionarios judiciales en el trato de casos individuales, a través de diversas técnicas, con el propósito de disponerlos de una manera más rápida, justa y económica". ${ }^{33}$

En efecto, el case management en los tribunales es ejecutado normalmente, pero no siempre, por los jueces, y, en general, el proceso es típicamente administrado en coordinación con el personal del tribunal, ${ }^{34}$ cuya participación es, sin embargo, frecuentemente invisibilizada. ${ }^{35}$ En este sentido, el case management es una tarea que se mantiene a medio camino entre la adjudicación y la administración judicial. ${ }^{36}$

Aún más, el case management no ve como opuestos la labor jurisdiccional con la gestión de los recursos del sistema, sino que entiende necesario preocuparse de su adecuado manejo para asegurar la justicia

\footnotetext{
${ }^{32}$ VORRASI, Kenneth M., "England's reform to alleviate the problems of civil process: A comparison of judicial case management in England and the United States", Journal of Legislation, 2004, Vol. 30, n ${ }^{\circ}$ 2, pp. 361-387.

${ }^{33}$ FIX-Fierro, Héctor, Courts, justice and efficiency: A socio-legal study of economic rationality in adjudication, Hart Publishing, Oxford, Portland (Oregon), 2003, p. 229.

${ }^{34}$ Martinuzzi, Alessandro, "Taking justice seriously: the problem of courts overload and the new model of judicial process", Civil Procedure Review, 2017, Vol. 8, № 1, p. 70.

${ }^{35}$ Holvast, Nina, "The power of the judicial assistant/law clerk: Looking behind the scenes at Courts in the United States, England and Wales, and the Netherlands", International Journal for Court Administration, 2016, Vol. 7, No 2, pp. 10 y ss.
}

${ }^{36}$ JeULAND, cit. (n. 29), pp. 7-8. 
a todos los usuarios y en todos los casos. De este modo, un activo case management supone una cierta voluntad judicial, una efectiva división del trabajo entre el personal del tribunal y los jueces, y además, una legislación que entregue al tribunal y al juez competencias y herramientas claras para la gestión de los casos. En la sección siguiente analizaremos las distintas dimensiones de este instituto, lo que permitirá precisar más su operatoria, contornos y desafíos que asume.

\section{DIMENSIONES DEL CASE MANAGEMENT}

\section{El macro case management o case management estructural}

El macro case management se enfoca en el conjunto de los casos o carga de trabajo del sistema. ${ }^{37}$ En esta perspectiva, se incluye cómo los casos son canalizados al interior de los tribunales ${ }^{38}$ y la manera en como estos se asignan a los jueces y juezas. ${ }^{39}$ En este último aspecto, se distinguen dos sistemas o modelos, el calendario maestro (master calendar) y la asignación y gestión individual de los casos ("individual case management”, "individual docket system", "single o individual calendar system").

En un sistema de calendario maestro, el caso no es asignado al conocimiento completo y exclusivo de un juez en particular, sino que cadajuez desarrolla una función particular durante el desarrollo del procedimiento. ${ }^{40}$ Sólo si se requiere la decisión judicial de un asunto o cuando el caso esté listo para la etapa de juicio, se asigna a un juez que esté disponible para su conocimiento y resolución. ${ }^{41}$ En cambio, en un sistema de calendario

\footnotetext{
${ }^{37}$ Spigelman, J.J., "Case management in New South Wales", trabajo preparado para la delegación judicial de India, Sidney, 2009, pp. 3-4, documento disponible en línea: https://www.supremecourt. justice.nsw.gov.au/Documents/Publications/Speeches/Pre-2015\%20Speeches/Spigelman/ spigelman_speeches_2009.pdf (fecha de visita: 23.03.2019).

${ }^{38}$ Usualmente basados en la cuantía o materia. En otros países, los grandes casos o más complejos son asignados a tribunales de mayor jerarquía. LEGG, Michael, Case Management and complex litigation, Federation Press, New South Wales, 2011, p. 3.

${ }^{39}$ Fabri, Marco; LangBroek, Philip M., "Is there a right judge for each case? A comparative study of case assignment in six European countries", European Journal of Legal Studies, 2007, Vol. 1, No 2, p. 292.

${ }^{40}$ FABRI, Marco, "Selected issues of judicial administration in a comparative perspective", en: FABRI, M.; LangBroek, P.M. (Eds.), The challenge of change for judicial systems. Developing a public administration perspective, IOS Press Ohmsha, Amsterdam - Berlin, 2000, p. 191.
}

${ }^{41}$ LeGG, cit. (n. 38), pp. 4-5. 
individual, el caso es asignado exclusivamente a un juez desde su inicio hasta su finalización, ${ }^{42}$ de forma que permanece con el mismo juez hasta que termine por juicio o en un acuerdo, el que mantiene la responsabilidad de su propio número de casos. ${ }^{43}$

Por otro lado, el case management estructural envuelve el uso de tracks o pistas procesales determinadas por normas legales o de origen judicial, que establecen de manera predeterminada para un conjunto de casos una cierta forma de tramitación. ${ }^{44}$ Así, una vez que el caso es ubicado en un track, el procedimiento que debe ser aplicado ya está determinado (distinto a otros tracks), entonces el tiempo y el esfuerzo requerido por el tribunal y las partes para la preparación del caso es minimizado gracias a su estandarización, aunque siempre existirán casos que requerirán un case management más a la medida lo que requiere el involucramiento directo del juez. $^{45}$

En suma, el objetivo en este macro case management es alcanzar una correcta distribución de la carga de trabajo del tribunal como un mecanismo para alcanzar el uso más eficiente de los limitados recursos y asegurar así que todos los casos sean oportunamente conocidos. ${ }^{46}$

\section{Micro case management o managerial judging}

La dimensión micro del case management se enfoca en el rol del Juez y la gestión de un caso individual o "dentro" de un caso. Se diferencia del macro case management en que el juez, dentro de los márgenes y las técnicas procesales que la ley prevé, adapta el rito y la ruta procesal a la medida de las necesidades del caso individual, lo que se ha denominado procedimiento de sastrería o tailoring procedure. ${ }^{47}$ Para ello el juez debe adoptar una activa gestión del procedimiento en las etapas preliminares, por medio de órdenes o resoluciones particulares, la calendarización de los pasos que deben ser

\footnotetext{
${ }^{42}$ FABRI, cit. (n. 40), p. 191.

${ }^{43}$ LANGBEIN, John, "The demise of trial in American civil procedure: How it happened, is it convergence with European civil procedure?", en: Van Rhee, C.H.; Uzelac, A. (Eds.), Truth and efficiency in civil litigation fundamental aspects of fact-finding and evidence-taking in a comparative context, Intersentia, Cambridge, Antwerp, 2012, p. 139.

${ }^{44}$ LeGG, cit. (n. 38), pp. 3-4.

${ }^{45}$ Ibíd., p. 5.

${ }^{46}$ Spigelman, cit. (n. 37), p. 7.

${ }^{47}$ LegG, cit. (n. 38), p. 3.
} 
tomados y su tiempo de duración.

Este micro case management opera cuando el caso ya ha sido asignado a un procedimiento específico. En este nivel, la actividad del juez complementa las regulaciones legales, mediante decisiones que se adaptan a las particularidades del caso. ${ }^{48}$

Para permitir esta adaptación, las formas del procedimiento deben configurarse e interpretarse de manera elástica y flexible, y los jueces estar dotados de los poderes necesarios. ${ }^{49}$

\section{DESAFÍOS Y PROBLEMAS ACTUALES DE LOS SISTEMAS DE JUS- TICIA}

La configuración actual del case management aparece como el producto de una compleja evolución que sintetizaremos como la sustitución progresiva de las concepciones ideológicas y teóricas individualistas sobre la función y operatoria de la justicia civil. ${ }^{50} \mathrm{Su}$ desarrollo se origina e impulsa por la interrelación de diversos factores, entre los cuales tres destacan por su mayor visibilidad y alcance. En primer lugar, una mayor preocupación por los alcances sociales y económicos de los procesos. ${ }^{51}$ En segundo lugar, la ampliación y reforzamiento de los derechos procesales, consecuencia de su reconocimiento en diversas constituciones y en convenciones internacionales sobre derechos humanos, ${ }^{52}$ entre ellos, especialmente, el acceso a la justicia. ${ }^{53}$ Finalmente, a estos factores se suma la extendida percepción que la administración de justicia civil se encuentra en crisis. ${ }^{54}$

Los tres factores mencionados han generado un cambio de paradigma

\footnotetext{
${ }^{48}$ Ibíd., p. 6.

${ }^{49}$ TAruffo, Michele, Paginas sobre justicia civil, Marcial Pons, Madrid, 2009, p. 121.

${ }^{50}$ Cappelletti, Mauro, "Vindicating the public interest through the courts: A comparativist's contribution", Buffalo Law Review, 1975-1976, Vol. 25, p. 689.

${ }^{51}$ CAPPELletti, Mauro, El testimonio de la parte en el sistema de la oralidad. Contribución a la teoría de la utilización probatoria del saber de las partes en el proceso civil, Editorial Platense, La Plata, 2002, T.I, pp. 214-215.

${ }^{52}$ Uzelac, Alan; Van Rhee, C.H., Revisiting procedural human rights: Fundamentals of civil procedure and the changing face of civil justice, Intersentia Metro, Cambridge, 2017.

${ }^{53}$ Véase. CAPpellettr, Mauro; Garth, Bryant, "Access to justice: The newest wave in the worldwide movement to make rights effective", Buffalo Law Review, 1977-1978, Vol. 27, pp. 181-292.

${ }^{54}$ Zuckerman, Adrian (Ed.), Civil justice in crisis, comparative perspectives of civil procedure, Oxford University Press, Oxford, 1999.
} 
tanto en la concepción de los objetivos asignados al proceso, como en la imagen sobre la que opera el sistema de justicia civil, cambios que explicaremos en las líneas que siguen.

1. El primer cambio de paradigma: La tridimensionalidad o trilogía de objetivos del proceso civil en los sistemas procesales civiles contemporáneos.

Tradicionalmente al proceso se le ha asignado una finalidad única, esto es, decidir el conflicto pronunciando decisiones justas o correctas. ${ }^{55} \mathrm{En} \mathrm{su}$ forma más pura, este objetivo se concentra sólo en la determinación de los derechos disputados entre las personas y limita la función de la justicia civil en proporcionar un foro neutral que se pone a disposición de los litigantes para evitar recurrir a la auto tutela. ${ }^{56}$ Este enfoque, denominado como "la vieja filosofía de la justicia según sus méritos", asume que siempre que un tribunal alcanza una decisión correcta sobre los hechos y el derecho, la justicia ha sido hecha, sin importar nada más. ${ }^{57}$ En esta perspectiva, no son relevantes el tiempo y/o los recursos utilizados, si ello da lugar a resultados legalmente correctos.

Esta concepción, se identifica con el modelo de proceso civil desarrollado en Europa en gran parte del siglo XIX, ${ }^{58}$ que lo consideraba como un asunto que solo interesaba a las partes. ${ }^{59}$ Este carácter privado significaba mucho más que el control privado de los derechos sustantivos, sino que también, la dominación de las partes sobre el desarrollo del procedimiento. ${ }^{60}$ Estas ideas se insertaron en gran parte de los códigos latinoamericanos. ${ }^{61}$

En la perspectiva comparada, por el contrario, se ha desarrollado un cambio de paradigma, de enfoque tridimensional, según el cual, mantener

\footnotetext{
${ }^{55}$ SoRABJI, John, English civil justice after Woolf and Jackson reform: A critical analysis, Cambridge University Press, London, 2014, p. 2.

${ }^{56}$ Uzelac, Alan, "Goals of civil justice and civil procedure in the contemporary world, global developments towards harmonisation (and back)", en: UzeLAC, A. (Ed.), Goals of civil justice and civil procedure in contemporary judicial systems, Editorial Springer International Publishing, Switzerland, 2014, p. 115.

${ }^{57}$ ZuCKeRMAN, cit. (n. 54), pp. 16 y ss.

${ }^{58}$ Este enfoque se mantiene hasta la actualidad, con matices, en el pensamiento jurídico continental. Damaska, Mirjan R., Evidence law adrift, Yale University Press, New Haven \& London, 1997, p. 120.

${ }^{59}$ Cappelletti y Garth, cit. (n. 2), p. 23

${ }^{60}$ Uzelac, cit. (n. 1), p. 115.

${ }^{61}$ Couture, Eduardo, "Trayectoria y destino del derecho procesal civil hispanoamericano", en Couture, E. (Ed.), Estudios de Derecho Procesal Civil, Eds. LexisNexis - Depalma, 2003, T.I, pp. 216 y ss.
} 
el tiempo y los costos que el litigio produce bajo estricto control es tan importante como alcanzar una decisión final correcta. ${ }^{62}$

En efecto, esta combinación de objetivos -ya reconocible en la obra de BenTHAM ${ }^{63}$ ha sido revalorizada en la actualidad, promoviéndose un equilibrio adecuado entre la cantidad de tiempo y dinero invertido en el juicio civil y la rigurosidad de la etapa de producción de la prueba, lo que constituye un punto de convergencia a nivel comparado. ${ }^{64}$ VAN RHEE y Uzelac, expresan en este sentido que: "En más y más jurisdicciones, la verdad en el litigio civil no es un objetivo absoluto. Al igual que con la mayoría de las cosas en la vida, la verdad tiene su precio, y este precio... debe ser proporcional a la importancia social del caso ". ${ }^{65}$

De hecho, esta trilogía de objetivos ha sido recogida en forma expresa en distintos sistemas jurídicos procesales. ${ }^{66}$

Asimismo, la necesidad de articular adecuadamente los tres factores señalados en el proceso judicial ha sido reforzada por la normativa y jurisprudencia sobre derechos humanos en materias procesales, ${ }^{67}$ lo que ha permitido una tendencia a la armonización de criterios a nivel internacional. ${ }^{68}$ En este sentido, VRANKEN indica que la complejidad, los altos costos y/o muchos retrasos violan tanto el derecho fundamental de acceso a la justicia

\footnotetext{
${ }^{62}$ ZucKerman, cit. (n. 54), pp. 16 y ss.

${ }^{63}$ Bentham, Jeremy, Scotch Reform; considered, with references, proposed in the late parliament, for the regulations of the courts, and the administration of justice, in Scotland, J. Ridgway, London, 1808, pp. 8-9.

${ }^{64}$ Convergencia que se reveló en la reunión de la Asociación Internacional de Derecho Procesal desarrollada en Florencia el año 2003. OтеIzA, Eduardo, "Civil procedure reforms in Latin America: The role of the judge and the parties in seeking a fair solution", The Supreme Court Review, 2010, Vol. 49, p. 225.

${ }^{65}$ VAN Rhee, C.H. y Uzelac, Alan, "The pursuit of truth in contemporary civil procedure. Revival of accuracy or a new balance in favour of effectiveness?", en: Van RHEe, C.H.; Uzelac, A. (Eds.), Truth and efficiency in civil litigation fundamental aspects of fact-finding and evidence-taking in a comparative context, Intersentia Cambridge, Anterwerp, Portland, 2012, p. 7.

${ }^{66}$ La Regla 1.1 del procedimiento civil de UK, indican que el Objetivo predominante es permitir a los tribunales tratar los casos de manera justa y a un costo proporcional al asunto y a la situación financiera de las partes, asegurando un tratamiento rápido y un uso apropiado de los recursos de la Corte. Véase Civil Procedure Rules. En USA, la regla 1 de las Reglas Federales disponen que deben interpretarse y administrarse para asegurar la determinación justa, rápida y económica de cada acción y procedimiento. Véase Federal Rules of Civil Procedure.

${ }^{67}$ SetTem, Ola Johan, Applications of the 'fair hearing'norm in ECHR article 6(1) to civil proceedings. With special emphasis on the balance between procedural safeguards and efficiency, Springer International Publishing, Switzerland, 2016.

${ }^{68}$ Diez, Luis María, Sistemas de derechos fundamentales, Thomson Civitas, Madrid, 2003, $1^{\circ}$ Edición, pp. 30 y ss.
} 
como el derecho fundamental a la igualdad, y que si bien decisiones correctas son el objetivo final del procedimiento civil, hacerlo de manera oportuna y económica se ha convertido en parte de él. ${ }^{69}$

De estas afirmaciones preliminares se derivan dos consecuencias importantes.

Primero, que los objetivos de alcanzar la decisión en un plazo razonable y a costos accesibles se van incorporando al elenco de garantías judiciales, infiltrándose progresivamente en el concepto de debido proceso. Así, Uzelac distingue dos elementos del derecho a un juicio justo: la eficiencia y la calidad de los procedimientos (E-element y Q-element). Las cuestiones asociadas a la duración de los procedimientos y los costos pertenecerían al elemento eficiencia (E-element) del derecho a un juicio justo. ${ }^{70}$ Segundo, que la eficiencia procesal, entendida como la capacidad de conseguir o maximizar un objetivo determinado, se amplía, incorporando las dimensiones de oportunidad y costos. ${ }^{71}$

Nótese que, en esta perspectiva, oportunidad y costos forman parte de la justicia procesal del caso, no de los costos generados a la sociedad o al Estado en la administración de justicia.

Los costos y la oportunidad de la decisión son factores que tradicionalmente han sido asociados con la eficiencia más que con la justicia. Sin embargo, si justicia significa darle efectividad a los derechos sustantivos de las partes, no resulta suficiente que el tribunal determine cuáles son esos derechos y a quien le corresponde, sin consideración de su costo y demora. En efecto, una sentencia puede aplicar correctamente el derecho a unos hechos correctamente establecidos y aun así llegar muy tarde para entregar una tutela efectiva ("justicia tardía, no es justicia")..$^{72}$ Del mismo modo, costos excesivos pueden debilitar la eficacia y justicia del procedimiento judicial. Así, no es poco frecuente que los costos incurridos por las partes en

\footnotetext{
${ }^{69}$ VRANKEN, J.B.M., "The impact of civil procedure reforms on the opportunities of substantive judgemade law", en: NomI, P. (Ed.), Procedure in the XXI"st century compared, Japan-Netherlands Institute, Tokyo, 2001, p. 14.

${ }^{70}$ Uzelac, Alan, “Accelerating Civil Proceedings in Croatia - A history of attempts to improve the efficiency of civil litigation", en: VAN RHEE, C.H. (Ed.), The law's delay. Essays on undue delay in civil litigation, Intersentia, Antwerp, 2004, p. 285.

${ }^{71}$ TARUfFo, cit. (n. 49), pp. 247 y ss.

${ }^{72}$ Zuckerman, Adrian, "Quality and Economy in Civil Procedure. The Case for Commuting Correct Judgments for Timely Judgments", Oxford Journal of Legal Studies, 1994, Vol. 14, pp. 360 y ss.
} 
la protección de sus derechos sean superiores al interés mismo en juego. ${ }^{73}$ En la literatura comparada se denomina a estas causas como de "valor negativo", muchas de las cuales ni siquiera llegan a los sistemas de justicia, suponiendo un problema de acceso.

En consecuencia, los imperativos y desafíos de la justicia actual obligan a encontrar un adecuado balance entre la calidad de la decisión, con la oportunidad en que ella es entregada y sus costos. La ausencia de estos factores es fuente de ineficiencia y una afrenta a los derechos de acceso a la justicia ${ }^{74} \mathrm{y}$ de igualdad ante la ley, ${ }^{75}$ debilitando la credibilidad y efectividad del sistema de justicia, y con ello, el Estado de Derecho. ${ }^{76}$

\section{El segundo cambio de paradigma: La perspectiva del conjunto de casos}

El segundo cambio de paradigma aparece vinculado a la imagen o escenario en que opera la justicia civil.

Según el trasfondo conceptual tradicional, los problemas y el diseño del proceso han sido concebidos pensando en un solo escenario, esto es, la del caso singular. Se trata de una relación tríadica, fuertemente individualista, donde sólo son visibles las dos partes enfrentadas en un caso ante un juez. Es la imagen que tradicionalmente nos transmiten nuestros códigos y leyes procesales. ${ }^{77}$ Esta perspectiva se refuerza por nuestra formación jurídica que nos enseña, precisamente, a considerar sólo la controversia en cuestión y sus méritos, pero no el funcionamiento del sistema jurídico, ni las consecuencias de la disputa para el conjunto de la litigación. ${ }^{78}$

A este paradigma se le ha denominado de la justicia individual o

\footnotetext{
${ }^{73}$ Spigelman, J.J., "The new Public Management and the Courts", Australian Law Journal, 2001, n 75 , pp. 749 y ss.

${ }^{74}$ Marinoni, Luiz Guilherme; Pérez Ragone, Álvaro; NúÑEz OJedA, Raúl, Fundamentos del proceso civil. Hacia una teoría de la adjudicación, Abeledo Perrot - Legal Publishing, Santiago, 2010, pp. 186 y ss.

${ }^{75}$ Cranston, Ross, How Law Works: The machinery and impact of civil justice, Oxford University Press, Oxford, 2006, p. 12.

${ }^{76}$ Rozakis, Christos, "The right to a fair trial in civil cases", Judicial Studies Institute Journal, 2004, Vol. 4, No 2, pp. 96 y ss.

${ }^{77}$ Biavati, Paolo, "Tendencias recientes de la justicia civil en Europa", Revista de Derecho Procesal (Rubinzal-Culzoni), 2008, Nº 1, p. 12.

${ }^{78}$ Newman, Jon, "Rethinking fairness: Perspectives on the litigation process", Yale Law Journal, 1985, Vol. $94, \mathrm{~N}^{\circ} 7$, p. 1650.
} 
enfoque atomizado, ${ }^{79}$ donde el sistema parece funcionar para la resolución de un sólo caso a la vez. Consistente con esta lógica, para alcanzar un resultado óptimo y justo, la totalidad de los recursos del sistema deberían estar a su disposición. El problema de este enfoque es su falta de visión de conjunto. Como afirma NEWMAN "aunque nos esforzamos escrupulosamente por lograr un resultado justo en la disputa individual, rara vez consideramos cómo ser justo con todos los que usan o quisieran usar el sistema de litigación". ${ }^{80}$

Por estas razones, aparece un nuevo paradigma que reconoce que la justicia y el proceso se administran a una multiplicidad de casos actuales y futuros, lo que exige organizar y distribuir proporcionalmente los recursos, con el objetivo que los fines del sistema pueda ser alcanzado en todos ellos. En efecto, los sistemas de justicia contemporáneos se enfrentan a otro gran desafío; la dramática realidad de procesar enormes volúmenes de trabajo, asumiendo, además, por exigencias normativas, la obligación de entregar a cada caso individual resultados de calidad, en un plazo razonable y con costos acotados.

La consideración del conjunto de casos se ha expresado en la idea de una "fila de espera" de todos aquellos casos y litigantes que esperan su turno para ser atendidos por los tribunales. Se trata, según Posner, del costo de oportunidad del tiempo que la gente pasa esperando en una fila que es “...literal para los acusados encarcelados en espera de juicio y para algunos propietarios "atrapados" en la litigación". ${ }^{81}$

Según este nuevo paradigma una perspectiva centrada exclusivamente en el caso individual, implica que alcanzar la justicia sustantiva para algunos puede constituir una denegación de justicia para otros, si es que no se logra un equilibrio y distribución equitativa de los recursos judiciales. ${ }^{82}$ La realidad es que el tiempo y los recursos humanos de los tribunales son limitados y, muchas veces, las decisiones sobre el progreso de un caso también afectan la disponibilidad de recursos judiciales para otros casos. ${ }^{83}$ TIDMARsh expresa

\footnotetext{
${ }^{79}$ La idea de "enfoque atomizado" es acuñada por VArgas PaVEz, Macarena; Fuentes MaureirA, Claudio, Introducción al Derecho Procesal, Nuevas Aproximaciones, Cuadernos Jurídicos, DER Ediciones Limitada, Santiago, 2018, pp. 109 y ss.

${ }^{80}$ Newman, cit. (n. 78), pp. 1643-1644.

${ }^{81}$ Posner, Richard A., "An economic approach to legal procedure and judicial administration", The Journal of Legal Studies, 1973, Vol. 2, No 2, pp. 445-446.

${ }^{82}$ SorabJi, cit. (n. 55), p. 164.

${ }^{83}$ Así, suspensiones de audiencias en un caso pueden aplazar otros casos. FrENCH, Robert, "The role of the trial court judge in pre-trial management", Federal Judicial Scholarship, 2004, N 10, documento
} 
esta tensión, consignando que "no podemos concentrarnos indebidamente en la entrega de una justicia más perfecta en el caso individual cuando muchos ciudadanos no reciben justicia de los tribunales en lo absoluto". ${ }^{84}$

Por ello, el gran desafío de los sistemas judiciales contemporáneos es el procesamiento masivo de casos. ${ }^{85}$ Según este enfoque, la capacidad y habilidad del sistema judicial para procesar los casos se asimila a un juego de suma cero, en tanto los recursos utilizados para un caso no estarán disponibles para otro, ${ }^{86}$ por lo que deben ser distribuidos equitativamente. ${ }^{87}$ En este contexto, lo importante es que la justicia se asegure para la totalidad de los asuntos y para ello los recursos del sistema deben ser divididos dando a cada uno lo que corresponda. ${ }^{88}$ Bajo esta mirada se vuelve inevitable y justificado que al conocer de un caso individual el juez debe igualmente tener en cuenta el resto de los casos de su tribunal. ${ }^{89}$

disponible en línea: http://www.austlii.edu.au/au/journals/FedJSchol/2004/10.html, Fecha de consulta 16 de abril de 2020. En Chile una idea similar se encuentra en la noción de "agenda del día" que manejan los tribunales reformados. En la agenda se establecen el listado de audiencias que serán vistas en un día particular. Esta agenda define el orden, el tipo de audiencia y la cantidad de tiempo predeterminada que un juez destinará a un caso particular. En este escenario, todo el tiempo extra que el juez dedique a un caso impactará en el tiempo para conocer los siguientes, lo que puede afectar el espacio de participación que tengan las partes y propiciar el desarrollo de ciertas prácticas polémicas como la imposición de límites de tiempo por parte de los jueces. Esto lleva a algunos académicos a hablar de una "tiranía de la agenda". PALOMo, Diego, "Cargas Probatorias Dinámicas ¿Es necesario darse toda esta vuelta?", en: Academia Parlamentaria de la Cámara de Diputados de Chile (Eds.), Cuadernos Hemiclo $N^{\circ} 12$, Segundas Jornadas Nacionales de Derecho Procesal y Reforma Procesal Civil, Cámara de Diputados de Chile, Valparaíso, 2013, p. 120. Con todo, dicha visión implica desconocer el problema de fondo, esto es, la gestión que existe detrás del diseño de la agenda y el importante rol que desempeña como articulador de recursos limitados, como el tiempo del tribunal y los costos de transacción que la resolución de la contienda supone.

${ }^{84}$ Tidmarsh, Jay, "The future of oral arguments", Loyola University Chicago Law Journal, 2016, Vol. 48, p. 486.

${ }^{85}$ Vease VAN RheE, cit. (n. 5); CADIET, Löic, "La justicia civil francesa entre eficiencia y garantías", Civil Procedure Review, 2013, Vol. 4, No 3, pp. 25 - 50.

${ }^{86}$ Marcus, Richard L., "Malaise of the litigation superpower", en: Zuckerman, A. (Ed.), Civil justice in crisis, comparative perspectives of civil procedure, Oxford University Press, Oxford, 1999, p. 91.

${ }^{87}$ Elliot, Donald E., "Managerial judging and the evolution of the procedure", The University of Chicago Law Review, 1986, Vol. 53, N² 2, p. 318.

${ }^{88}$ CADIET, Löic, "Pour une «Théorie générale du procés»”, Ritsumeikan Law Review, 2011, № 28, p. 144.

${ }^{89}$ LANGBeIn, John, cit. (n. 43), p. 142. 


\section{EL SURGIMIENTO DE NUEVOS PRINCIPIOS PROCESALES COMO BASE DEL CASE MANAGEMENT}

El cambio de paradigma identificado en la sección anterior no solo ha dado pie al surgimiento del case management, si no que a nuevos $\mathrm{y}$ distintos principios procesales que permiten hacerlo operativo. Se trata de los principios de proporcionalidad y de cooperación, que analizaremos brevemente.

\section{La proporcionalidad como concepto articulador de los nuevos paradigmas}

Dado que las ideas recién expuestas no suponen desconsiderar los requerimientos de justicia de los casos individuales, ni criticar normas o instrumentos procesales específicos, sino que pensar cómo pueden operar, desplegando sus valores y virtudes en el conjunto del sistema, se llega inevitablemente a la necesidad de una adecuada conciliación y balance entre ambas perspectivas.

En este sentido, un concepto de justicia que comprende no sólo a los litigantes de un caso individual, sino también a los actuales y futuros usuarios, nos conduce a cambios en la forma de enfrentar los desafíos de las demoras y gastos..$^{90}$ En esta lógica, la proporcionalidad basada en la complejidad o importancia del asunto parece constituirse en una respuesta aceptable y cuyo complemento es la flexibilidad necesaria para identificar y manejar los diversos casos que ingresan al sistema.

Para CAPONI, la proporcionalidad todavía tiene que explorar el potencial axiológico y ético en el campo de la justicia, pero está tallada en el artículo 1 de las Reglas de Procedimiento Civil inglesas, donde se dice que la tramitación de un caso incluye, entre otras cosas: "atribuirle una parte apropiada de los recursos del tribunal, teniendo en cuenta la necesidad de reservar recursos para otros casos". ${ }^{91}$

La proporcionalidad, según SoRABJI, tiene dos aspectos. El primero implica que el costo y tiempo ocupado en un caso individual debe ser proporcional al valor de lo demandado. Se trata de alcanzar un balance entre el costo de decidir los casos mediante la aplicación correcta del derecho a

\footnotetext{
${ }^{90}$ Newman, cit. (n. 78), p. 1644.

${ }^{91}$ CAPONI, Remo, "II principio di proporzíonalitá nella giustizia civile: prime note sistematiche", Rivista trimestrale di diritto e procedura civile, 2011, Vol. 65, № 2, p. 394.
} 
los hechos verdaderos y el beneficio que se derivará de dar efecto al derecho sustantivo entre las partes. Este aspecto se denomina proporcionalidad introspectiva (inward-looking) o proporcionalidad individual, enfocada al caso que inmediatamente está conociendo un tribunal..$^{92} \mathrm{El}$ segundo aspecto significa que ninguna demanda individual debería utilizar más que una parte proporcional de los recursos del sistema de justicia. En este caso, el equilibrio que debe alcanzarse es entre el valor positivo de proseguir un caso individual para una determinación en su mérito y los requerimientos para facilitar la misma determinación en otros casos individuales. Este aspecto se denomina proporcionalidad externa (outward-looking) o proporcionalidad colectiva, y su foco está en el derecho de los litigantes, como un conjunto, más allá de cualquier caso en particular. ${ }^{93}$

Como se observa, la proporcionalidad incorpora un elemento holístico que supera una evaluación limitada al caso individual, ${ }^{94}$ lo que se traduce en la necesidad de distinguir y priorizar entre los múltiples casos según su valor, privado y social, y a su complejidad, en atención a los limitados recursos del sistema judicial. ${ }^{95}$

Este nuevo paradigma es coherente con las teorías sobre la litigación informadas por principios democráticos, que evalúan sus resultados por la capacidad de los ciudadanos para acceder a los tribunales para la protección de sus derechos o la compensación de sus daños. ${ }^{96}$ Además, estas consideraciones encuentran su común denominador en el enfoque del acceso a la justicia, que se centra en dos propósitos básicos del sistema de justicia del Estado: el sistema debe ser igualmente accesible para todos y conducir a resultados que sean individual y socialmente justos. ${ }^{97}$ Esto significa que el sistema de justicia debe permitir a todos el acceso a la justicia en un plano

\footnotetext{
${ }^{92}$ SorabJi, cit. (n. 55), p. 167.

${ }^{93}$ Ibíd.

${ }^{94}$ Diferenciándose de la idea de razonabilidad. Tronson, Brenda, "Towards proportionality. The "quick, cheap and just" balance in civil litigation", en: Picker, C.B.; SeIDman, G.I. (Eds.), The dynamism of civil procedure. Global trends and developments. Serie Ius Gentium: Comparative Perspective on Law and Justice $\mathrm{N}^{\circ}$ 48, Springer International Publishing, 2016, p. 185.

${ }^{95}$ KLement, Alon; Neeman, Zvika, "Civil justice reform: A mechanism design framework", Journal of Institutional and Theoretical Economics, 2008, Vol. 164, No 1, p. 53.

${ }^{96}$ HadFIELD, Gilian K., "Exploring economic and democratic theories of civil litigation: Differences between individual and organizational litigants in the disposition of federal civil cases", Stanford Law Review, 2005, Vol. 57, № 5, p. 1292.

${ }^{97}$ Cappelletti y Garth, cit. (n. 53), p. 182.
} 
de igualdad. ${ }^{98}$

Tradicionalmente, este principio de igualdad procesal ha sido entendido limitadamente, esto es, para asegurar, tanto como sea posible, que los litigantes en los casos individuales sean tratados en forma igualitaria en el procedimiento. ${ }^{99}$ Sin embargo, la igualdad no está limitada a la consideración de las partes de la litigación individual, sino que tiene un aspecto colectivo, ya que todos los ciudadanos tienen un derecho de acceso al sistema de justicia para hacer efectivos sus derechos. ${ }^{100}$

Si bien esta concepción supone cierta limitación de los derechos de participación de los litigantes en el procedimiento individual -especialmente, cuando su ejercicio sea desproporcionado, abusivo o desmedido- esta limitación pasa a ser un medio necesario para asegurar los derechos del conjunto de ciudadanos. Así, la racionalización no implica socavar la provisión de justicia, sino que una condición para alcanzarla.

En efecto, aspirar a una justicia perfecta y completa, sin restricciones, llevaría a excesos de tiempo y costos que la sociedad no puede afrontar. ${ }^{101} \mathrm{Sin}$ embargo, tampoco parece razonable afirmar que el Estado no debe proveer ningún recurso para alcanzar la rectitud de la decisión. Desde que ninguno de estos extremos es sostenible, lo que podemos reclamar razonablemente es algo entre ambos extremos, esto es, a un procedimiento que se esfuerce por proporcionar una medida razonable de protección de los derechos, conmensurable con los recursos que podemos gastar en justicia. ${ }^{102}$

En suma, asegurar una alternativa de justicia para todos, en plazos razonables y a costos acotados, teniendo presente el conjunto de casos exige racionalizar los recursos del sistema, lo que supone que alguien la ejecute en los casos individuales. Lo que se busca, en palabras de Cappelletti, es "articular la rapidez y la eficiencia con la justicia; la libertad individual con

\footnotetext{
${ }^{98}$ Moreno CAtena, Víctor, "Crisis de la justicia y reformas procesales", en: Ministerio de Justicia de España (Eds.), Primer Congreso de Derecho Procesal de Castilla y León, Centro de Publicaciones, Valladolid, 1988, pp. 83-84.

${ }^{99}$ SorABJI, cit. (n. 55), p. 165.

${ }^{100}$ Ibid., p. 166.

${ }^{101}$ Galanter, Marc, "Access to justice in a world of expanding social capability", Fordham Law Journal, 2009, Vol. 37, № 1, p. 126.

102 ZuCKerman, Adrian, "Reform in the shadow of lawyers' interests", en: ZucKerman, A.; Cranston, R. (Eds.), Reform of civil procedure: Essays on "Access to Justice”, Oxford University Press, 1995, p. 74.
} 
la igualdad de oportunidades". ${ }^{103}$

2. La superación de la dicotomía tradicional dispositivo/oficialidad: el principio de la cooperación procesal como una nueva síntesis sobre la conducción del proceso

Para hacerse cargo tanto del desafío de procesar la gran demanda que recae sobre los sistemas de justicia, como de articular en los casos particulares las exigencias de calidad, oportunidad y costos, se ha propuesto entregar a los jueces el control de la litigación, ${ }^{104}$ lo que ha sido considerado como una mega tendencia del proceso civil, desde la segunda mitad del siglo XX. ${ }^{105}$

La asunción compartida es que existe una relación entre un juez activo en la conducción de la litigación y una mejora en la eficiencia. ${ }^{106} \mathrm{En}$ efecto, el enfoque de la gestión del caso de las partes constituyó la imagen en Francia, a partir del Código de 1806 y de Inglaterra hasta $1999,{ }^{107}$ lo que se basada en el predominio casi sin contrapesos y conceptualmente extremo del principio dispositivo. Se hablaba así, del modelo tradicional donde la iniciación, conducción y presentación de los procedimientos es confiado a las partes. ${ }^{108} \mathrm{El}$ problema es que por sus intereses individuales, las partes o sus abogados siempre exigirán el máximo de recursos del sistema, como el tiempo judicial, y de resguardos procesales para su caso.

Por esta razón, distintos sistemas procesales han propiciado que los jueces, tanto por su posición institucional como por su capacidad de equilibrar los intereses públicos y privados en juego, asuman la responsabilidad de controlar el desarrollo del conjunto de la litigación, distribuyendo y racionalizando los recursos del sistema, bajo un criterio de proporcionalidad. Aparece, de este modo, el judicial case management, que se constituye en

\footnotetext{
${ }^{103}$ Cappelletti, Mauro, cit. (n. 7), p. 886.

${ }^{104}$ Dodson, Scott; KlebBa, James M., "Global civil procedure trends in the twenty-first century", Boston College International \& Comparative Law Review, 2011, Vol. 34, № 1, pp. 1-26.

${ }^{105}$ Domes, Tanja, "Efficiency in the relationship between the judge and the parties: A perspective on the future Swiss code of civil procedure", en: Uzelac, A.; Van Rhee, C.H. (Eds.), Access to justice and the judiciary. Towards new European standards of affordability, quality and efficiency of civil adjudication, Intersentia Metro, Antwerp, 2009, p. 78.

${ }^{106}$ Andrews, cit. (n. 27), pp. 253-289.

${ }^{107}$ Sorabi, cit. (n. 14), p. 2.

${ }^{108}$ BeLl, Evans, “Judicial case management”, Judicial Studies Institute Journal, 2009, № 2, p. 78.
} 
un instrumento de eficiencia para alcanzar diversos objetivos del sistema, generando un enfoque distinto del proceso de litigación y modificando, además, el tradicional rol del juez determinado por el carácter individualista y el contenido privado del litigio civil. En este enfoque, el case management implica una transferencia de la responsabilidad en el manejo de la litigación, desde los litigantes y sus abogados, hacia los jueces, ${ }^{109}$ lo que se no se traduce en el reemplazo del principio dispositivo por el predominio del principio de la oficialidad, sino que en el surgimiento de un nuevo principio procesal. ${ }^{110}$

En efecto, el case management privilegia la cooperación entre las partes y el juez, ${ }^{111}$ como sucede en Europa ${ }^{112}$ y Estados Unidos. ${ }^{113}$ En este contexto OTEIZA entiende el case management como la dirección y control activo del Juez sobre los procedimientos con consulta de las partes, ${ }^{114}$ concepto en el que subyace la idea de colaboración.

En consecuencia, en el concepto y evolución del case management desaparece la dicotomía juez activo - partes pasivas, propia de la imagen del sistema inquisitivo, o bien, partes activas-juez pasivo de los sistemas adversariales. Por el contrario, aparece una nueva relación procesal juez activo - partes activas, que se genera a partir del control y gestión judicial de la litigación, en un entorno que supone y promueve la cooperación de las partes en todo el proceso. ${ }^{115}$

Este modelo cooperativo supone, igualmente, que debe existir alguien que tome las decisiones en caso de desacuerdo, ya que de otro modo no sería posible avanzar en el proceso. En consecuencia, la cooperación requiere de case management por el tribunal. ${ }^{116}$

${ }^{109}$ ZANDER, Michael, Cases and materials on the English legal system, Cambridge University Press, Cambridge, 2007, $10^{\circ}$ ed., p. 125.

${ }^{110}$ AguirrezÁBAl, Maite; Pérez RAgone, Álvaro, “Aportes para una conducción colaborativa del proceso civil chileno: pensando una nueva justicia", Revista de Derecho Privado, n 35, p.302.

${ }^{111}$ CABRAL, cit. (n. 16), pp. 15 y ss.

${ }^{112}$ Así, en Europa lo nuevo es que el rol activo del juez se enmarca en el deber de cooperar. Así debe ser entendido en varias jurisdicciones. VAN RHEE, cit. (n. 11), pp. 77 y 78.

${ }^{113}$ Las notas del Comité sobre la enmienda de la regla 1 en el año 2015 de las Reglas Federales de USA, consignan que: "La abogacía efectiva es coherente con - y de hecho depende - del uso cooperativo y proporcional del procedimiento". Véase Federal Rules of Civil Procedure.

${ }^{114}$ Oteiza, cit. (n. 64), pp. 227 y ss.

${ }^{115}$ Como se recoge en las reglas de procedimiento civil de la European Law Institute y UNIDROIT. VAn RheE; C.H., "Towards Harmonised European Rules of Civil Procedure: Obligations of the Judge, the Parties and their Lawyers", Access to Justice in Eastern Europe, 2020, Vol. 1, N 6, pp. 6-33.

${ }^{116}$ STURNER, Rolf, "Some European remarks on a new joint project of the American law institute and UNIDROIT", The International Lawyer, 2000, Vol. 34, No 3, p. 1082. 


\section{VI. ¿ES REALMENTE EL CASE MANAGEMENT UN CAMBIO DE PARADIGMA PROCESAL?}

Hasta ahora nos hemos centrado en describir el case management como un nuevo paradigma acerca del control del proceso y su desarrollo, mostrándose como una noción distinta a la del juez director, como una tercera respuesta más compleja y sofisticada a la pregunta de cómo hacer frente a los grandes desafíos que el sistema de justicia debe enfrentar. Para demostrar estas aserciones, en la presente sección haremos un contraste entre ambos institutos.

$\mathrm{Al}$ respecto, recordemos que entre nosotros el case management se ha confundido o entendido como equivalente de la idea de dirección del proceso. Esta metáfora surgió como un nuevo paradigma en respuesta a los problemas que ocasionaba el control exclusivo de las partes en el litigio y por la consideración de la existencia de intereses públicos en el proceso. Entre estos factores se encontraba el objetivo social de igualar materialmente a las partes, controlando que la superioridad social o económica de una de ellas se tradujera en una superioridad procesal y, por otra parte, evitar comportamientos dilatorios y obstructivos de las partes. La sociedad tenía un interés general en lograr soluciones prontas, igualitarias, verdaderas y justas. Una estrategia fue impedir el control de las partes y en su lugar se enfatizó la necesidad de establecer la dirección del proceso en manos del juez. ${ }^{117}$

La Ordenanza Procesal Civil austriaca de Klein de 1895 fue su hito inicial donde el procedimiento civil modificó su carácter predominantemente privado tomando una connotación pública en el cual el proceso sirve al bien común. ${ }^{118}$ Este código fue producto de los cambios sociales ocurridos por la revolución industrial y de demandas articuladas sobre la oralidad, la inmediación y la libre evaluación de la prueba. ${ }^{119}$ En este sentido Cappelletti afirmaba que en el sistema procesal civil austriaco de la ZPO de 1895, el juez civil dejó de estar "fuera" del proceso, y que "sus poderes de dirección

\footnotetext{
${ }^{117}$ López, cit. (n. 6), pp. 29 y 30.

${ }^{118}$ VAN RheE, C.H., cit. (n. 5), p.3.

119 Oberhammer, P.; Domes, T., "Improving the efficiency of civil justice: Some remarks from an Austrian perspective", en: Van Rhee, C.H.; Uzelac, A. (Eds.), Civil justice between efficiency and quality: From ius commune to the Cepej, Intesentia Metro, Antwerp, 2008, p. 63.
} 
y de control fueron notablemente aumentados". ${ }^{120}$

La doctrina procesal clásica empezó a utilizar la expresión en alemán "Prozessleintung des Richters" y sus análogos, "dirección judicial del proceso" en español, "direzione del proceso" en italiano y "direction $o$ maitrise du process" en Francia. ${ }^{121}$ Lo mismo ocurrió en el medio latinoamericano. ${ }^{122}$

En doctrina se ha dicho que esta dirección judicial del proceso tiene dos dimensiones, material y formal. La primera, se refiere a los elementos que pueden influir en la decisión que debe adoptar el juez al final del proceso, en tanto que la segunda, atiende al control de la regularidad formal o técnica de los actos del procedimiento para que éste se desarrolle pasando de una fase a otra. ${ }^{123}$

Sin embargo, más allá de esta síntesis centrada únicamente en las potestades del juez, el concepto de dirección del proceso carece de un contenido teórico claro y definido, ni ha permitido orientar una práctica judicial consistente. En diferentes textos sólo se recogen nociones generales $\mathrm{y}$, más bien, abstractas sobre la función, contenido y operatoria de un juez director del proceso. ${ }^{124}$ Incluso, el tema mismo de la dirección judicial del proceso ha sido escasamente estudiado por la doctrina, al punto que Tavolari lo ha criticado por vago, abstracto y, principalmente, insuficiente. ${ }^{125}$

Esta es una de las razones por las que el case management configura una noción o categoría conceptual nueva, y en especial, autónoma, que responde a desafíos, tendencias y problemas distintos, generando un nuevo enfoque para analizar diversos problemas del proceso y del sistema de justicia. Una segunda razón para sostener su autonomía conceptual es que es posible identificar de manera precisa importantes diferencias entre esta y la dirección

${ }^{120}$ CAPpelletti, Mauro, El proceso civil en el derecho comparado. Las grandes tendencias evolutivas. (trad. de Santiago Sentis Melendo), Ediciones Jurídicas Europa-América S.A., Buenos Aires, 1973, $1^{\circ}$ ed., p. 61.

${ }^{121}$ López, cit. (n. 6), p. 34

${ }^{122}$ OteizA, Eduardo, "Relaciones entre las partes, los jueces y los abogados", en: Storme, M.; GómEZ, C. (Coords.), XII Congreso Mundial de Derecho Procesal, Universidad Nacional Autónoma de México, México D.F., 2005, T. III., pp. 199-120.

${ }^{123}$ Montero A., Juan; Gómez C., José L.; Barona V., Silvia; Montón R., Alberto, Derecho Jurisdiccional. Parte General, Tirant lo Blanch, Valencia, 2000, $10^{\circ}$ edición, T. I, pp. 334 y ss.

${ }^{124}$ Por ejemplo, Anabalón consignaba que "el juez no debe ser ni un autómata ni un dictador". AnABALON, Carlos, Tratado práctico de derecho procesal civil chileno, Librotec Ltda., 1996, 2ª ed., T.I, p. 15.

${ }^{125}$ TaVolari, Raúl, "Bases y criterios para el nuevo proceso civil chileno", en: PAlomo, D.; DE La Oliva, A. (Coords.), Proceso civil. Hacia una nueva justicia civil, Editorial Jurídica, Santiago, 2007, pp. 41-42. 
judicial del proceso, que dan cuenta de la mayor complejidad y sofisticación de la primera. En las líneas siguientes sintetizaremos las más relevantes.

\section{La preocupación por el conjunto de casos}

Esta característica, que ya hemos tratado, genera la necesidad de compatibilizar las exigencias del caso individual con todos los otros casos que requieren igual atención del tribunal, lo que se traduce en la necesidad de racionalizar los escasos recursos disponibles, esto es, en organizarlos de manera de hacerlos más eficientes, bajo criterios individual y socialmente equitativos, donde la proporcionalidad se ha constituido en un principio orientador.

Esto constituye una importante diferencia entre las nociones de case management y de dirección del proceso, la que no considera el tratamiento del conjunto de casos, sino que, más bien, el rol del juez frente a un caso individual. En efecto, con la dirección del proceso se buscaba, fundamentalmente, igualar a las partes en el proceso, mediante el ejercicio de los poderes de oficio del juez, especialmente, en materia probatoria. ${ }^{126}$

En consecuencia, el concepto de dirección judicial del proceso, no permite comprender y resolver la complejidad de articular y compatibilizar las necesidades de los casos individuales con la del resto de los casos. En contraposición, en la lógica del case management, se tiene en cuenta que existen otros casos que requerirán la infraestructura, recursos humanos y tiempo del sistema judicial. En este sentido, el juez amplía su rol, pasando a convertirse en responsable del conjunto de la litigación y no solo de un procedimiento individual.

\section{Confluencia entre los ámbitos jurisdiccionales y de gestión}

En el case management se identifican conexiones entre la actividad judicial, propiamente tal, con la de otros estamentos y órganos encargados de la gestión de los tribunales. Ello incluye mecanismos que aseguren la coordinación, la colaboración y la adecuada organización entre y dentro de los tribunales. ${ }^{127}$

\footnotetext{
${ }^{126}$ López, cit. (n. 6), p. 35

127 PÉrez Ragone, Álvaro, "An approach and general overview to framing the structure of the court system and case management”, Tiajin Conference (IAPL), International Association of Procedural
} 
Así, se genera en el case management un punto de encuentro entre la gerencia del proceso y la del despacho judicial, esto es, entre ámbitos y lógicas jurídico- procesales con otras ciencias y lógicas, especialmente del ámbito de la administración.

En cambio, en la metáfora de la dirección judicial del proceso la única imagen que aparece y es reconocible es la del juez ejerciendo sus potestades en la conducción de un procedimiento individual, es decir, responde a la lógica que denominamos paradigma de la justicia individual. No hay referencias a los aspectos que componen la dimensión macro del case management, ni a la coordinación de los procesos desarrollados por jueces y órganos de gestión necesarios para mover los casos desde su ingreso hasta su disposición.

\section{Cooperación de los litigantes}

También el case management involucra la activa participación de las partes, donde la cooperación emerge como un principio fundamental. Aparecen aquí diversas herramientas para asegurar esta cooperación, como, por ejemplo, los denominados contratos procesales, esto es, la adaptación del procedimiento por acuerdo de las partes, característicos de la legislación francesa y actualmente presentes en Brasil. ${ }^{128}$

Esta cooperación y la participación activa de los litigantes exceden de la idea de poderes del juez, con los que se identifica la idea de dirección judicial del proceso.

\section{Ampliación de los fines del proceso}

Como hemos visto, en el case management la preocupación por las demoras y costos adquieren una mayor relevancia, equiparándose con el objetivo tradicional de alcanzar la corrección de la decisión. Esta trilogía de objetivos requiere que los jueces resuelvan las tensiones que se presentan entre estos objetivos, considerando tanto el caso individual como el conjunto de casos.

\footnotetext{
Law, Tianjin, 2017, pp. 16-17.

${ }^{128}$ García Odgers, Ramón, "El case management en el proceso civil francés. Los contratos procesales y la flexibilidad como herramientas de eficiencia", en: Machado, P.; Larroucau, J. (Coords.), Estudios de Derecho Procesal. Libro de amigos del Profesor Dr. Raúl Núñez Ojeda, DER Ediciones, Santiago, 2019, pp. 193-229.
} 
Además, también se amplía la finalidad del sistema de justicia en cuanto a la forma cómo deben resolverse los asuntos. Un ejemplo de lo anterior ha sido, desde hace varias décadas, el fuerte surgimiento de mecanismos alternativos de resolución de disputas, conocidos por su sigla en inglés como ADR. Pues bien, una de las principales herramientas del case management es el fomento por parte del sistema de justicia de estos mecanismos, sea antes del proceso, como la mediación, o durante su desarrollo, referido al importante rol que los jueces desempeñan en las conciliaciones judiciales.

Esto pone en disputa la idea de que una solución justa o correcta es siempre sinónimo de una decisión jurisdiccional. ${ }^{129}$ La misma literatura sobre $\mathrm{ADR}$ da cuenta de este cambio, en la medida que la letra "A" inicialmente entendida como "alternativa", hoy significa "apropiada", hablándose de resolución apropiada de disputas. ${ }^{130}$

Lo anterior supone aceptar que la sentencia es solo una de las formas por las cuales un conflicto puede ser resuelto, existiendo otros mecanismos igualmente legítimos y valiosos. En este punto el case management incorpora la idea de que parte del análisis que los tribunales y jueces realizan respecto del caso que están conociendo es un juicio acerca de cuál es el método de resolución más apropiado para ponerle término, considerando tanto las particularidades del caso individual como el conjunto de casos que conocen los tribunales.

En cambio, en el origen y desarrollo de la metáfora de la dirección del proceso no se reconocían estos métodos distintos a la sentencia con la profundidad y aceptación con la que hoy en día cuentan, máxime si, como se ha anotado, esta idea surgió asociada a la búsqueda de la igualdad de las partes, especialmente, con el ejercicio de los poderes judiciales en materia probatoria, esto es, para alcanzar una sentencia justa.

\footnotetext{
${ }^{129}$ Un prejuicio recurrente respecto de los ADR, es que estos son solamente impulsados por los sistemas judiciales de common law y no así por sistemas de tradición continental. Un ejemplo que refuta este prejuicio es el sistema procesal civil alemán, el cual, al menos desde 1985, incentiva constantemente por medio del juez la posibilidad de los acuerdos entre las partes. Véase: LANGBeIn, John, "The German advantage in Civil Procedure", The University of Chicago Law Review, 1985, Vol. 52, No 4, p. 831.

${ }^{130}$ MenKel-Meadow, Carrie, "Mediation, arbitration, and Alternative Dispute Resolution (ADR)", en Wright, J. D. (Editor), International Encyclopedia of the Social and Behavioral Sciences, Elsevier, Amsterdam, 2015, p. 70.
} 


\section{CONCLUSIONES}

Se ha demostrado que el case management es una manifestación de la dinámica evolutiva del proceso civil que se configura como una respuesta a los desafíos y problemas que enfrentan los sistemas de justicia contemporáneos.

Hoy la conducción del proceso supone articular diversos objetivos y procesar un incremento de casos nunca antes vistos. Por esta razón eficiencia y justicia no se oponen, sino que se complementan. Una noción de justicia ampliada, que no solo supone decisiones legalmente correctas, sino que oportunas y a costos accesibles, debe necesariamente ser eficiente para garantizar su acceso a toda la población.

En respuesta a este trascendental desafío emergen nuevos principios como la proporcionalidad y la cooperación. La proporcionalidad aparece como un criterio que permite balancear valores difíciles de regular en abstracto, incorporando conceptualmente elementos de justicia distributiva y de eficiencia. A su vez, la cooperación reconoce que las partes y el juez en un trabajo colaborativo conducen el procedimiento de manera de conciliar la consecución de los diversos objetivos y fines procesales. Ambos principios traen aparejados la necesidad de diseños procesales flexibles y dúctiles.

Estos desarrollos permiten afirmar que el case management marca la superación del paradigma del juez director del proceso. Esto queda en evidencia por sus alcances más amplios, así como por la integración de los distintos actores del proceso legal hacia renovados fines del proceso.

En este sentido, el case management resulta un aporte para la reflexión acerca de nuestros sistemas de justicia ya que configura un nuevo marco teórico, cuya importancia es que permite visibilizar y considerar nuevas variables que resultan claves para el entendimiento y solución de problemas que en la actualidad aquejan a nuestro sistema de justicia. 


\section{BIBLIOGRAFÍA CITADA}

\section{a) Doctrina}

AguirrezÁbal, Maite; Pérez Ragone, Álvaro, “Aportes para una conducción colaborativa del proceso civil chileno: pensando una nueva justicia", Revista de Derecho Privado, 2018, n 35, pp. 293-326.

Anabalón, Carlos, Tratado práctico de derecho procesal civil chileno, Librotec Ltda., Santiago, 1996, $2^{\mathrm{a}}$ edición, T.I.

ANDREws, Neil, "La combinación de la administración pública y privada de la justicia civil", Revista de Derecho P. Universidad Católica de Valparaíso, 2012, Vol. XXXIX, pp. 253-289 (trad. al castellano de Álvaro Pérez Ragone y Ramón García Odgers).

Andrews, Neil, English civil procedure. Fundamentals of the new civil justice system, Oxford University Press, New York, 2003.

BelL, Evans, "Judicial case management", Judicial Studies Institute Journal, $2009, \mathrm{~N}^{\circ} 2$.

Bentham, Jeremy, Scotch Reform; considered, with references, proposed in the late parliament, for the regulations of the courts, and the administration of justice, in Scotland, J. Ridgway, London, 1808.

Berizonce, Roberto, "El principio de legalidad formal bajo el prisma de la constitución "normatizada", Revista del Instituto Colombiano de Derecho Procesal, 2014, $\mathrm{N}^{\circ} 40$.

Biavati, Paolo, "Tendencias recientes de la justicia civil en Europa", Revista de Derecho Procesal (Rubinzal-Culzoni), 2008, No 1 .

Bravo, Pablo, "Hacia la reforma del proceso civil en Chile", Revista General de Derecho Procesal (Iustel), 2013, № 29 (enero), pp. 1-36.

CABral, Antonio, "News trends and perspective on case management: proposals on contract procedures and case assignment management", Tiajin Conference (IAPL), International Association of Procedural Law, Tiajin, 2017.

CADIET, Löic, "Pour une «Théorie générale du procés»", Ritsumeikan Law Review, 2011, No 28.

CADIET, Löic, "La justicia civil francesa entre eficiencia y garantías", Civil Procedure Review, 2013, Vol. 4, No 3.

Cappelletti, Mauro; Garth, Bryant, International encyclopedia of comparative law XVI, Mohr - Siebeck, Tubingen; Martinus Nijhoff Publishers, Leiden, 1987, T.I.

CAPPelletti, Mauro, El proceso civil en el derecho comparado. Las grandes tendencias evolutivas. (trad. de Santiago Sentis Melendo), Ediciones Jurídicas Europa-América S.A., Buenos Aires, 1973, $1^{\circ}$ ed.

Cappelletti, Mauro; Garth, Bryant, "Access to justice: The newest wave in the worldwide movement to make rights effective", Buffalo Law Review, 1977- 
1978, Vol. 27.

CAPPELletti, Mauro, "Vindicating the public interest through the courts: A comparativist's contribution", Buffalo Law Review, 1975-1976, Vol. 25.

CAPPElletti, Mauro, El testimonio de la parte en el sistema de la oralidad. Contribución a la teoría de la utilización probatoria del saber de las partes en el proceso civil, Editorial Platense, La Plata, 2002, T.I.

Cappelletti, Mauro, "Social and Political Aspects of Civil Procedure: Reforms and Trends in Western and Eastern Europe", Michigan Law Review, 1971, Vol. 69, Nº 5 .

CAPONI, Remo, "II principio di proporzíonalitá nella giustizia civile: prime note sistematiche", Rivista trimestrale di diritto e procedura civile, 2011, Vol. 65, $\mathrm{N}^{\mathrm{o}} 2$.

COUture, Eduardo, "Trayectoria y destino del derecho procesal civil hispanoamericano", en Couture, E. (Ed.), Estudios de Derecho Procesal Civil, Eds. LexisNexis - Depalma, 2003, T.I.

Cranston, Ross, How Law Works: The machinery and impact of civil justice, Oxford University Press, Oxford, 2006.

Damaska, Mirjan, Evidence law adrift, Yale University Press, New Haven - London, 1997.

Didier JR., Fredie; Arruda, Teresa (Coords.), CPC Brasileiro Traduzido para a lingua espanhola, Código de Proceso Civil Brasleiño de 2015, traducao Renzo Cavani, Editoria Juspodivm, Salvador, 2018.

DiEz, Luis María, Sistemas de derechos fundamentales, Thomson Civitas, Madrid, 2003, $1^{\text {o }}$ Edición.

Dodson, Scott; KlebBA, James M., "Global civil procedure trends in the twenty-first century", Boston College International \& Comparative Law Review, 2011, Vol. 34, No 1 .

Domes, Tanja, "Efficiency in the relationship between the judge and the parties: A perspective on the future Swiss code of civil procedure", en: UzELAC, A.; VAn Rhee, C.H. (Eds.), Access to justice and the judiciary. Towards new European standards of affordability, quality and efficiency of civil adjudication, Intersentia Metro, Antwerp, 2009.

Elliot, Donald E., "Managerial judging and the evolution of the procedure", The University of Chicago Law Review, 1986, Vol. 53, № 2.

FABri, Marco; LANGBroek, Philip M., "Is there a right judge for each case? A comparative study of case assignment in six European countries", European Journal of Legal Studies, 2007, Vol. 1, № 2.

FABRI, Marco, "Selected issues of judicial administration in a comparative perspective", en: FABri, M.; LANGBROEK, P.M. (Eds.), The challenge of change for judicial systems. Developing a public administration perspective, IOS Press Ohmsha, Amsterdam - Berlin, 2000. 
FandiÑo, Marco; Sucunza, Matías, "Cambios organizativos y nuevo rol de los operadores como premisas para el éxito de la oralidad en la justicia civil del Perú", Gaceta Civil \& Procesal Civil, 2019, № 74.

FIX-FIerro, Héctor, Courts, justice and efficiency: A socio-legal study of economic rationality in adjudication, Hart Publishing, Oxford, Portland (Oregon), 2003.

FRENCH, Robert, "The role of the trial court judge in pre-trial management", Federal Judicial Scholarship, 2004, $\mathrm{N}^{\circ}$ 10, documento en línea: http://www. austlii.edu.au/au/journals/FedJSchol/2004/10.html, fecha de consulta: 16 de abril de 2020.

Galanter, Marc, "Access to justice in a world of expanding social capability”, Fordham Law Journal, 2009, Vol. 37, № 1.

GARCIA Odgers, Ramón, El case management en perspectiva comparada. Teoría, evolución histórica, modelos comparados y un caso en desarrollo, Tirant Lo Blanch, Valencia, 2020.

Garcia Odgers, Ramón, "El surgimiento del judicial case management: una síntesis evolutiva del control judicial del proceso civil en Europa", Revista de Estudios Histórico Jurídicos, 2019, № 41.

García Odgers, Ramón, "El case management en el proceso civil francés. Los contratos procesales y la flexibilidad como herramientas de eficiencia", en: Machado, P.; Larroucau, J. (Coords.), Estudios de Derecho Procesal. Libro de amigos del Profesor Dr. Raúl Núñez Ojeda, DER Ediciones, Santiago, 2019.

HADFIELD, Gilian K., "Exploring economic and democratic theories of civil litigation: Differences between individual and organizational litigants in the disposition of federal civil cases", Stanford Law Review, 2005, Vol. 57, № 5.

Holvast, Nina, "The power of the judicial assistant/law clerk: Looking behind the scenes at Courts in the United States, England and Wales, and the Netherlands", International Journal for Court Administration, 2016, Vol. 7, № 2.

Jeuland, Emmanuel, "Toward a New Court Management and the rise of the Court manager - General Report", Tiajin Conference (IAPL), International Association of Procedure Law, Tianjin, 2017.

Klement, Alon; Neeman, Zvika, "Civil justice reform: A mechanism design framework", Journal of Institutional and Theoretical Economics, 2008, Vol. 164, $\mathrm{N}^{\mathrm{o}} 1$.

Kunn, Thomas S., La estructura de las revoluciones cientificas, Fondo de Cultura Económica, México D.F., 2010, $3^{\mathrm{a}}$ edición.

LangBeIn, John, "The demise of trial in American civil procedure: How it happened, is it convergence with European civil procedure?", en: VAN RHEE, C.H.; UzELAC, A. (Eds.), Truth and efficiency in civil litigation fundamental aspects of fact-finding and evidence-taking in a comparative context, Intersentia Cambridge, Antwerp, 2012. 
Langbein, "The German advantage in Civil Procedure", The University of Chicago Law Review, 1985, Vol. 52, № 4.

LegG, Michael, Case Management and complex litigation, Federation Press, New South Wales, 2011.

LóPez, Diego, Nuevas tendencias en la Dirección Judicial del Proceso, Módulo de Formación, Escuela judicial "Rodrigo Lara Bonilla", Colombia, 2004.

MARCus, Richard L., "Malaise of the litigation superpower", en: ZuCKERMAN, A. (Ed.), Civil justice in crisis, comparative perspectives of civil procedure, Oxford University Press, Oxford, 1999.

Marcus, Richard L., "Reassessing the magnetic pull of mega cases on procedure", DePaul Law Review, 2001, N 51.

Marinoni, Luiz Guilherme; Pérez Ragone, Álvaro; NúÑez OJedA, Raúl, Fundamentos del proceso civil. Hacia una teoría de la adjudicación, Abeledo Perrot - Legal Publishing, Santiago, 2010.

Martinuzzi, Alessandro, "Taking justice seriously: the problem of courts overload and the new model of judicial process", Civil Procedure Review, 2017, Vol. 8, $\mathrm{N}^{\mathrm{o}} 1$.

Menkel-Meadow, Carrie, "Mediation, arbitration, and Alternative Dispute Resolution (ADR)", en Wright, J. D. (Editor), International Encyclopedia of the Social and Behavioral Sciences, Elsevier, Amsterdam, 2015, pp. 70-74.

Montero A., Juan; Gómez C., José L.; Barona V., Silvia; Montón R., Alberto, Derecho Jurisdiccional. Parte General, Tirant lo Blanch, Valencia, 2000, $10^{\circ}$ edición, T. I.

Moreno Catena, Víctor, "Crisis de la justicia y reformas procesales", en: Ministerio de Justicia de España (Eds.), Primer Congreso de Derecho Procesal de Castilla y León, Centro de Publicaciones, Valladolid, 1988.

Newman, Jon, "Rethinking fairness: Perspectives on the litigation process", Yale Law Journal, 1985, Vol. 94, № 7.

Oberhammer, P.; Domes, T., "Improving the efficiency of civil justice: Some remarks from an Austrian perspective", en: Van Rhee, C.H.; Uzelac, A. (Eds.), Civil justice between efficiency and quality: From ius commune to the Cepej, Intesentia Metro, Antwerp, 2008.

OteizA, Eduardo, "Case management and judicial management: five perspectives with a common aim", International Journal of Procedural Law, 2018, Vol. 8, $\mathrm{N}^{\mathrm{o}} 1$.

OteizA, Eduardo, "Civil procedure reforms in Latin America: The role of the judge and the parties in seeking a fair solution", The Supreme Court Review, 2010, Vol. 49.

OteizA, Eduardo, "Relaciones entre las partes, los jueces y los abogados", en: Storme, M.; Gómez, C. (Coords.), XII Congreso Mundial de Derecho Procesal, Universidad Nacional Autónoma de México, México D.F., 2005, T. III. 
Palomo, Diego, "Cargas Probatorias Dinámicas ¿Es necesario darse toda esta vuelta?", en: Academia Parlamentaria de la Cámara de Diputados de Chile (Eds.), Cuadernos Hemiclo $N^{\circ}$ 12, Segundas Jornadas Nacionales de Derecho Procesal y Reforma Procesal Civil, Cámara de Diputados de Chile, Valparaíso, 2013.

Palomo, Diego, "Sobre la conducta procesal de algunos jueces. De vuelta con la unidimensionalidad de la eficiencia y la potestad conciliatoria como excusas", Ius et Praxis, 2014, Año 20, $\mathrm{N}^{\circ} 1$.

PÉREZ RAgONE, Álvaro, "La revalorización de la audiencia preliminar o preparatoria: Una mirada desde la justicia distributiva en el proceso civil", Revista de Processo, 2016, Vol. 252, pp. 405 - 435.

Pérez Ragone, Álvaro, "An approach and general overview to framing the structure of the court system and case management", Tiajin Conference (IAPL), International Association of Procedural Law, Tianjin, 2017.

PosNer, Richard A., "An economic approach to legal procedure and judicial administration", The Journal of Legal Studies, 1973, Vol. 2, № 2. $\mathrm{N}^{\mathrm{o}} 2$.

ReSNIK, Judith, "Managerial judges", Harvard Law Review, 1982, Vol. 96,

ResniK, Judith, "Los jueces como directores del proceso", Revista de Processo, 2017, Vol. 42, № 268 (trad. cast. de María Emilia Mamberti y Francisco Verbic).

RIEGO, Cristian, "El sistema de case management y su aplicación en el contexto chileno", Revista Sistemas Judiciales, 2014, Vol. 18.

Rozakis, Christos, "The right to a fair trial in civil cases", Judicial Studies Institute Journal, 2004, Vol. 4, № 2.

SetTEM, Ola Johan, Applications of the 'fair hearing' norm in ECHR article 6(1) to civil proceedings. With special emphasis on the balance between procedural safeguards and efficiency, Springer International Publishing, Switzerland, 2016.

Spigelman, J.J., "Case management in New South Wales", trabajo preparado para la delegación judicial de India, Sidney, 2009, 32 pp., disponible en línea: https://www.supremecourt.justice.nsw.gov.au/Documents/Publications/Speeches/ Pre-2015\%20Speeches/Spigelman/spigelman_speeches_2009.pdf (fecha de visita: 23.03.2019).

Spigelman, J.J., "The new Public Management and the Courts", Australian Law Journal, 2001, $\mathrm{N}^{\circ} 75$.

SORABJI, John, "Managing claims", Tiajin Conference (IAPL), International Association of Procedural Law, Tiajin, 2017.

SORABJI, John, English civil justice after Woolf and Jackson reform: A critical analysis, Cambridge University Press, London, 2014.

STURNER, Rolf, "Some European remarks on a new joint project of the American law institute and UNIDROIT", The International Lawyer, 2000, Vol. 34, $\mathrm{N}^{\circ} 3$. 
TARuffo, Michele, Paginas sobre justicia civil, Marcial Pons, Madrid, 2009.

TARUFFo, Michele, "Poderes probatorios de las partes y del juez en Europa", DOXA, Cuadernos de Filosofia del Derecho, 2006, № 29, pp. 249-271.

TAVOLARI, Raúl, "Bases y criterios para el nuevo proceso civil chileno", en: Palomo, D.; De La Oliva, A. (Coords.), Proceso civil. Hacia una nueva justicia civil, Editorial Jurídica, Santiago, 2007.

Tavolari, Raúl, "Prólogo", en: Delgado, J.; NúÑEz, R. (Coords.), Recursos procesales. Problemas actuales, DER Ediciones, Chile, 2017.

Tidmarsh, Jay, "The future of oral arguments", Loyola University Chicago Law Journal, 2016, Vol. 48.

Tronson, Brenda, "Towards proportionality. The "quick, cheap and just" balance in civil litigation", en: PICKer, C.B.; SeIDMAn, G.I. (Eds.), The dynamism of civil procedure. Global trends and developments, serie Ius Gentium: Comparative Perspective on Law and Justice $\mathrm{n}^{\circ} 48$, Springer International Publishing, Switzerland, 2016.

Uzelac, Alan; Van Rhee, C.H., "The Metamorphoses of Civil Justice and Civil Procedure: The Challenges of New Paradigms - Unity and Diversity", en: Uzelac, A.; Van Rhee, C.H. (Eds.), Transformation of Civil Justice, Springer International Publishing AG, Switzerland, 2018.

Uzelac, Alan; Van Rhee, C.H., Revisiting procedural human rights: Fundamentals of civil procedure and the changing face of civil justice, Intersentia Metro, Cambridge, 2017.

Uzelac, Alan, "Goals of Civil Justice General Report", en: Maleshin, D. (Ed.), Civil procedure in cross-cultural dialogue, International Association of Procedural Law Russian Federation, Statut, Moscú, 2012.

UzELAC, Alan, "Goals of civil justice and civil procedure in the contemporary world, global developments towards harmonisation (and back)", en: UzELAC, A. (Ed.), Goals of civil justice and civil procedure in contemporary judicial systems, Springer International Publishing, Switzerland, 2014.

Uzelac, Alan, "Accelerating Civil Proceedings in Croatia - A history of attempts to improve the efficiency of civil litigation", en: VAN RHEE, C.H. (Ed.), The law's delay. Essays on undue delay in civil litigation, Intersentia, Antwerp, 2004.

VAN RHEE, C.H., Judicial case management and efficiency in civil litigation, Intersentia, Antwerp, Oxford, Portland, 2008.

VAN RHEE, C.H., "Case management in Europe: A modern approach to civil litigation", International Journal of Procedural Law, 2018, Vol. 8, № 1, pp. 65-84.

VAN RheE, C.H., "Obligations of the parties and their lawyers in civil litigation: The ALI/UNIDROIT principles of transnational civil procedure", en: Adolphsen, Jens; Goebel, Joachim; HaAs, Ulrich; Hess, Burkhard; Kolmann, Stephan; WÜRDINGER, Markus, (Eds.), Festschrift für Peter Gottwald zum 70 
Geburtstag, C.H. Beck, München, 2014.

VAN RHEE, C.H., "Tradiciones europeas en el procedimiento civil: Una introducción", Revista de Estudios de la Justicia, 2011, No 15 (trad. cast. de Graciela Hermosilla Riobó y Carolina Sandoval Flores).

VAn RheE; C.H., "Towards Harmonised European Rules of Civil Procedure: Obligations of the Judge, the Parties and their Lawyers", Access to Justice in Eastern Europe, 2020, Vol. 1, N 6.

Vargas Pavez, Macarena; Fuentes Maureira, Claudio, Introducción al Derecho Procesal, Nuevas Aproximaciones, Cuadernos Jurídicos, DER Ediciones Limitada, Santiago, 2018.

Vorrasi, Kenneth M., "England's reform to alleviate the problems of civil process: A comparison of judicial case management in England and the United States", Journal of Legislation, 2004, Vol. 30, N².

VRANKEN, J.B.M., "The impact of civil procedure reforms on the opportunities of substantive judge- made law", en: NomI, P (Ed.), Procedure in the XXIst century compared, Japan-Netherlands Institute, Tokyo, 2001.

ZANDER, Michael, Cases and materials on the English legal system, Cambridge University Press, Cambridge, 2007, $10^{\circ}$ ed.

Zuckerman, Adrian (Ed.), Civil justice in crisis, comparative perspectives of civil procedure, Oxford University Press, Oxford, 1999.

ZucKerman, Adrian, "Reform in the shadow of lawyers' interests", en: Zuckerman, A.; Cranston, R. (Eds.), Reform of civil procedure: Essays on "Access to Justice”, Oxford University Press, Oxford, 1995.

Zuckerman, Adrian, "Quality and Economy in Civil Procedure. The Case for Commuting Correct Judgments for Timely Judgments", Oxford Journal of Legal Studies, 1994, Vol. 14.

b) Normas

Civil Procedure Rules (U.K.), disponibles en http://www.justice.gov.uk/ courts/procedure-rules/civil.

Federal Rules of Civil Procedure (Washington, U.S. Government Printing Office, 2014). 